\title{
Editorial: Advances in Health Education Applying E-Learning, Simulations and Distance Technologies
}

\author{
Andre W. Kushniruk* \\ School of Health Information Science \\ University of Victoria \\ Victoria, British Columbia, Canada \\ E-mail: andrek@uvic.ca \\ *Corresponding author
}

\begin{abstract}
This special issue of the KM\&EL international journal is dedicated to coverage of novel advances in health professional education applying eLearning, simulations and distance education technologies. Modern healthcare is beginning to be transformed through the emergence of new information technologies and rapid advances in health informatics. Advances such as electronic health record systems (EHRs), clinical decision support systems and other advanced information systems such as public health surveillance systems are rapidly being deployed worldwide. The education of health professionals such as medical, nursing and allied health professionals will require an improved understanding of these technologies and how they will transform their healthcare practice. However, currently there is a lack of integration of knowledge and skills related to such technology in health professional education. In this issue of the journal we present articles that describe a set of novel approaches to integrating essential health information technology into the education of health professionals, as well as the use of advanced information technologies and e-Learning approaches for improving health professional education. The approaches range from use of simulations to development of novel Web-based platforms for allowing students to interact with the technologies and healthcare practices that are rapidly changing healthcare.
\end{abstract}

Keywords: Health professional education; Health informatics; Simulations; eLearning; Web-based learning; Virtual learning environments; Health information technology

Biographical notes: Andre W. Kushniruk is a Professor in Health Information Science at the University of Victoria, in Victoria, Canada. He is a fellow of the American College of Medical Informatics. Dr. Kushniruk conducts research in a number of areas including usability engineering, electronic health records, human-computer interaction in healthcare as well as health professional education involving information technology. His work is known internationally as he has published over 100 articles in the area of health informatics and he has advised on variety of national and international committees and projects. Dr Kushniruk has held academic positions at a number of Canadian universities and worked with a number of major hospitals and hospitals in Canada, the United States and internationally. In addition, he has worked on developing innovative health informatics educational programs and curricula in Canada as well as internationally. He holds undergraduate degrees in Psychology and Biology, as well as a MSc in Computer Science and a $\mathrm{PhD}$ in Cognitive Psychology from McGill University. 


\section{Introduction}

This special issue of the KM\&EL international journal is dedicated to coverage of advances in health professional education applying e-Learning, simulations and distance education technologies. The world of healthcare is being transformed through health information systems and e-health innovations. This includes widespread implementation of systems such as electronic health records, medical decision support systems, Webbased conferencing, imaging technologies and other related innovations. However, worldwide there are serious issues regarding adoption of e-health innovations, with adoption rates in many countries remaining at a low level despite current efforts. As a consequence, many nations are now embarking on massive spending programs to modernize healthcare through widespread introduction of these technologies throughout healthcare systems. However, health professional education has remained to catch up to include and integrate health information systems into the daily and routine training of all health professionals, including medical, nursing, physiotherapy, social work and other allied health professional students. In addition, students in the area of health informatics need access to a wide range of new health information systems and need to interact with the type of systems they will ultimately be developing for health professionals. This will be needed to ensure that health professionals are able to work effectively and efficiently with these new technologies, and that health informatics students will become designers and implementers of safe and usable systems.

\section{Preview of Papers}

In this special issue we include papers that describe advances in e-learning in healthcare, Web-based education, educational healthcare simulations, and integration of health information systems into health professional training. In addition, papers include recent advances in distance learning technologies related to health professional training and education. In order to ensure that the move towards modernizing healthcare globally using health information technology is to succeed, advances will need to be put into place to ensure that health professional students as well as health informatics students have had a wide range of exposure to these emerging technologies that they will encounter with greater certainty upon graduation. How to best integrate these technologies into their training and education in a way that is both effective and natural is still a major research issue. In addition, the special issue focuses on new approaches to providing health professional students, health informatics students as well as continuing health professional education, with distance education and remote access to the ever growing repertoire of health information systems.

The call for contributions resulted in submission of research papers describing a range of approaches to modernizing health professional education and to introducing advances in health information technology into health professional curricula. The paper by Constance Johnson and colleagues (2011) describes one such innovation in the use of virtual environments to create active learning approaches for nursing students. Virtual environments can provide an enhanced learning environment for distance education and in the paper by Angie Lee and Zane Berge (2011), a broad perspective on use of Second Life in healthcare education is discussed in the context of providing potential to improve patient safety. The paper by Househ et al. (2011) provides a description of use of Webbased conferencing to support knowledge production activities and continuing online education for researchers and educators in the area of evidence-based drug detailing. Another area where innovative information technology is beginning to be applied is in 
creating advanced learning environments and on-line simulations for integrating advanced technologies directly into education that will be used by students upon graduation (e.g. electronic health records). Along these lines, in the paper by Watanabe et al. (2011), a simulation environment is described that provides students in health informatics with the opportunity to learn about both hospital workflow and electronic health record information technology. In the paper by Borycki et al., the authors describe current educational issues in modernizing the education of health professionals with access to the electronic systems and tools currently used in practice. They go on to describe a novel Web-based platform for allowing remote access by students to a range of different types of working health information systems, including electronic health records. In related work Joe et al. (2011) describe creation of an electronic medical case simulator that can be used to present cases and training to the education of medical students, while at the same time providing students with training on use of electronic health record systems. In the paper by Gonzalez et al. (2011) the use of information and communication technologies in hospital classrooms is discussed. The adaptation of a hematology curriculum to a web environment using RDF and a web portfolio system is described by Enoksson et al. (2011). Finally, in the paper by MacDonald et al. (2011) work in gathering information and needs analysis for development of a physician online health and wellness resource is described. Although the papers cover a diverse range of novel approaches, designs and systems, they are all focused on improving education and training using the latest advances in both e-Learning and health informatics. It is hoped that the papers will stimulate further work and related advances in the future, with the goal of improving health professional education and ultimately healthcare through improved education.

\section{Acknowledgements}

I would like to thank the Editors-in-Chief Dr. Maggie M. Wang and Dr. Stephen J.H. Yang for the opportunity to put together a set of articles on such a diverse and interesting topic areas in e-Learning and technology-supported education. This issue would not have been possible without their support, guidance and patience.

\section{References}

1. Borycki, E., Bellwood, P., Campbell, R., Joe, R.S., \& Armstrong, B. (2011). Educating health professionals about emerging health information technologies: Removing the barriers to adoption. Knowledge Management \& E-Learning: An International Journal, 3(1), 51-62.

2. Enoksson, F., Naeve, A., \& Hellstrom-Lindberg, E. (2011). Using a hematology curriculum in a web portfolio environment. Knowledge Management \& E-Learning: An International Journal, 3(1), 84-97.

3. Gonzalez, C.S., Toledo, P., Alayon, S., Munoz, V., \& Meneses, D. (2011). Using information and communication technologies in hospital classrooms: SAVEH Project. Knowledge Management \& E-Learning: An International Journal, 3(1), $72-$ 83.

4. Househ, M.S., Kushniruk, A.W., Maclure, M., Carleton, B., \& Cloutier-Fisher, D. (2011). Virtual knowledge production within a physician educational outreach 
program. Knowledge Management \& E-Learning: An International Journal, 3(1), 24-34.

5. Joe, R.S., Otto, A., \& Borycki, E. (2011). Designing an electronic medical case simulator for health professional education. Knowledge Management \& E-Learning: An International Journal, 3(1), 63-71.

6. Johnson, C.M., Corazzini, K.N., \& Shaw, R. (2011). Assessing the feasibility of using virtual environments in distance education. Knowledge Management \& ELearning: An International Journal, 3(1), 5-16.

7. Lee, A., \& Berge, Z.L. (2011). Second Life in healthcare education: Virtual environment's potential to improve patient safety. Knowledge Management \& ELearning: An International Journal, 3(1), 17-23.

8. MacDonald, C.J., Archibald, D., Puddester, D., \& Whiting, S. (2011). Managing disruptive physician behavior: First steps for designing an effective online resource. Knowledge Management \& E-Learning: An International Journal, 3(1), 98-115.

9. Watanabe, K., Okada, M., \& Yamamoto, K. (2011). EPR (Electronic Patient Record) Laboratory - Simulated environment to learn about a hospital EPR system. Knowledge Management \& E-Learning: An International Journal, 3(1), 35-50. 